\title{
Video Article \\ Speciation and Bioavailability Measurements of Environmental Plutonium Using Diffusion in Thin Films
}

\author{
Ruslan Cusnir $^{1}$, Philipp Steinmann ${ }^{2}$, Marcus Christl $^{3}$, François Bochud ${ }^{1}$, Pascal Froidevaux $^{1}$ \\ ${ }^{1}$ Institute of Radiation Physics, Lausanne University Hospital \\ ${ }^{2}$ Federal Office of Public Health, Bern, Switzerland \\ ${ }^{3}$ Laboratory of Ion Beam Physics, ETH Zurich
}

Correspondence to: Pascal Froidevaux at Pascal.Froidevaux@chuv.ch

URL: https://www.jove.com/video/53188

DOI: doi: $10.3791 / 53188$

Keywords: Engineering, Issue 105, Plutonium, bioavailability, DGT, AMS, speciation, humic acids, NOM, radionuclide, radioactivity

Date Published: 11/9/2015

Citation: Cusnir, R., Steinmann, P., Christl, M., Bochud, F., Froidevaux, P. Speciation and Bioavailability Measurements of Environmental Plutonium Using Diffusion in Thin Films. J. Vis. Exp. (105), e53188, doi:10.3791/53188 (2015).

\section{Abstract}

The biological uptake of plutonium $\mathrm{Pu}$ in aquatic ecosystems is of particular concern since it is an alpha-particle emitter with long half-life which can potentially contribute to the exposure of biota and humans. The diffusive gradients in thin films technique is introduced here for insitu measurements of Pu bioavailability and speciation. A diffusion cell constructed for laboratory experiments with Pu and the newly developed protocol make it possible to simulate the environmental behavior of $\mathrm{Pu}$ in model solutions of various chemical compositions. Adjustment of the oxidation states to $\mathrm{Pu}(\mathrm{IV})$ and $\mathrm{Pu}(\mathrm{V})$ described in this protocol is essential in order to investigate the complex redox chemistry of plutonium in the environment. The calibration of this technique and the results obtained in the laboratory experiments enable to develop a specific DGT device for in-situ Pu measurements in freshwaters. Accelerator-based mass-spectrometry measurements of Pu accumulated by DGTs in a karst spring allowed determining the bioavailability of $\mathrm{Pu}$ in a mineral freshwater environment. Application of this protocol for Pu measurements using DGT devices has a large potential to improve our understanding of the speciation and the biological transfer of Pu in aquatic ecosystems.

\section{Video Link}

The video component of this article can be found at https://www.jove.com/video/53188/

\section{Introduction}

Plutonium is an artificial radionuclide present in the environment as a result of the global fallout following the nuclear bomb tests and nuclear accidents. The redox chemistry of plutonium has important implications for its migration and biogeochemical cycling in environmental aquatic systems $^{1}$. Plutonium has a complex chemistry and can exist in four oxidation states (III, IV, V, VI) at the same time. Therefore, the distribution of redox species of plutonium in natural waters is extremely sensitive to local chemical environment ${ }^{2,3}$. The oxidation state of plutonium also depends on the origin of the source - this statement being mostly relevant for contaminated environments and disposal sites. Reduced plutonium species (+III and +IV) are found predominately in anoxic environments and originate from global fallout and stocked waste effluents, while higher oxidation states $(+\mathrm{V}$ and $+\mathrm{VI})$ can be found among decay products of other actinides and in oxic environments ${ }^{4}$.

The mobility and the environmental behavior of plutonium can be predicted to some extent from the redox speciation. Plutonium in +III and +IV oxidation states exists predominately in solid phase and has increased capacity to sorb to inorganic colloids and naturally occurring organic matter (NOM) molecules. Plutonium in +III and +IV oxidation states is considered to be less mobile. More soluble oxidized forms of plutonium $(+\mathrm{V} \text { and }+\mathrm{VI},+\mathrm{V} \text { being most likely })^{5}$ can potentially contribute to a higher biological transfer to aquatic organisms due to higher mobility. Nevertheless, in presence of NOM, particularly of humic acid, $\mathrm{Pu}(\mathrm{V})$ is being reduced ${ }^{17}$, shifting the partitioning several orders of magnitude in favor of precipitation. Despite the fact that the reduction rate of $\mathrm{Pu}(\mathrm{V})$ to $\mathrm{Pu}(\mathrm{IV})$ is 4 to 5 orders of magnitude faster than the reverse reaction, remobilization of $\mathrm{Pu}(\mathrm{IV})$ under oxidizing conditions may also take place ${ }^{1}$. Recent experimental data on mineral sediments amended with $\mathrm{Pu}(\mathrm{IV})$ and subjected to natural oxidizing conditions have demonstrated that the concentration of soluble Pu in aqueous phase increased over time ${ }^{1,6}$. The authors explain it by oxidative desorption of $\mathrm{Pu}(\mathrm{IV})$ and formation of more soluble $\mathrm{Pu}(\mathrm{V})$ and $\mathrm{Pu}(\mathrm{VI})$ species. Oxidation of $\mathrm{Pu}(\mathrm{IV}) \mathrm{may}$ also occur due to naturally encountered manganese oxides ${ }^{7}$. These observations are important for bioavailability modeling and environmental risk assessment of waste disposal and contaminated sites.

Studies on bioavailability and speciation of plutonium is a challenging task in both laboratory and in-situ conditions. Low environmental concentrations, the variability of redox species and the interactions with natural colloids make it difficult to simulate the biogeochemical behavior of plutonium. The technique of diffusive gradients in thin films (DGT) based on the diffusion of free and labile contaminant species through a polyacrylamide (PAM) gel is widely used for environmental measurements of trace elements ${ }^{8}$. A DGT sampler represents a three-layer device made of a binding phase (for the majority of trace metals it is Chelex resin contained in the PAM gel), diffusive gel layer (PAM gel of varying thickness) and a filter membrane protecting the gel and holding the assembly together. Thin films of polyacrylamide gel, consisting of $85 \%$ of 
water, enable free and labile complex species to diffuse more rapidly than plutonium bound to large NOM molecules or natural colloidal particles. A set-up designed to study plutonium diffusion in thin PAM gel films in laboratory conditions is called a diffusion cell ${ }^{9}$.

A diffusion cell is a two-compartment vessel where two separate compartments are interconnected by an opening of a given surface. The opening, i.e., the window between the two chambers contains a disc of diffusion gel of a given thickness. We constructed a Teflon cell with two $100 \mathrm{ml}$ compartments and a circular diffusion window $1.7 \mathrm{~cm}$ in diameter. One compartment is removable, facilitating the assembly. A $0.5 \mathrm{~cm}$ wide groove carved around the diffusion window on the fixed compartment serves to place the diffusive gel disc. The groove depth should be similar to PAM gel thickness intended for use. We choose to work with a $0.39 \mathrm{~mm}$ PAM gel, thus the groove depth in our diffusion cell is 0.39 $\mathrm{mm}$. A detailed picture of the diffusion cell is given in Figure 1.

When a solution initially containing plutonium is placed into one compartment $(\mathrm{A})$, diffusing Pu species will establish a concentration gradient in the gel and will start to accumulate in the second compartment (B), initially containing a solution of the same chemical composition without $\mathrm{Pu}$. The initial concentration of Pu species in compartment $\mathrm{A}$ is defined such that it remains constant or changes very little (by $1 \%-2 \%$ at most) throughout the diffusion experiment. Plotting the amount of diffused Pu versus time provides a means to analyze the mobility of Pu species prevailing in the different simulated environmental conditions. Diffusion in thin films provides a valuable alternative for studies on Pu mobility and speciation and can be successfully applied in field conditions ${ }^{10}$. One can replace the diffusion cell by a passive sampler, manufactured with the PAM diffusive gel and Chelex resin as the binding phase, which serves to accumulate diffusing Pu species. Such a sampler can be exposed in field conditions - the amount of Pu accumulated in the resin will be indicative of the speciation and the bioavailability of Pu in the respective environment ${ }^{10}$.

In this work, we used a diffusion cell to investigate the mobility of $\mathrm{Pu}(\mathrm{IV})$ and $\mathrm{Pu}(\mathrm{V})$ species and their interactions with $\mathrm{NOM}$ in laboratory conditions. Furthermore, we applied large passive DGT samplers of a surface of $105 \mathrm{~cm}^{2}$ to study the bioavailability of Pu in a karstic spring of the Swiss Jura Mountains (Venoge River) where a significant fraction of Pu was found in the intracellular parts of aquatic mosses in a previous work $^{11}$. Because of the very low level of plutonium present in this pristine environment, accelerator-based mass spectrometry (AMS) techniques available at ETH Zurich were used to measure plutonium isotopes.

\section{Protocol}

\section{Plutonium Tracer Preparation}

1. $\mathrm{Pu}(\mathrm{IV})$ tracer preparation

1. From the Pu stock solution transfer an appropriate aliquot containing the desired amount of Pu for the experiment into a $25 \mathrm{ml}$ glass beaker. Work with $10 \mathrm{~Bq}$ of ${ }^{239} \mathrm{Pu}$ at a time.

2. Add $1 \mathrm{ml}$ concentrated $\mathrm{HNO}_{3}, 0.6 \mathrm{ml} 1 \mathrm{M} \mathrm{NaHSO}_{4}, 0.4 \mathrm{ml}$ concentrated $\mathrm{H}_{2} \mathrm{SO}_{4}$. Evaporate to dryness on a hot plate. Heat slowly at $200{ }^{\circ} \mathrm{C}$ at the beginning to avoid acid projection.

3. Once no liquid is left in the beaker, anneal the residue at $400{ }^{\circ} \mathrm{C}-500^{\circ} \mathrm{C}$ until no white fumes emanate. The residue is white when cooled and soluble in the buffer chosen for the experiment.

Note: $\mathrm{Pu}(\mathrm{IV})$ source prepared in this way can be stored dry up to several months ${ }^{12}$

2. $\mathrm{Pu}(\mathrm{V})$ tracer preparation $^{13}$

1. Pu oxidation

1. Transfer an aliquot from the Pu stock solution into a plastic $20 \mathrm{ml}$ liquid-scintillation vial with a leakproof cap. Work with $10 \mathrm{~Bq}$ of ${ }^{239} \mathrm{Pu}$ at a time. Add $0.01 \mathrm{ml}$ of $0.01 \mathrm{M} \mathrm{KMnO}_{4}$ and leave the mixture in the dark for at least $6 \mathrm{hr}$.

2. $\mathrm{Pu}(\mathrm{VI})$ extraction

1. Prior to extraction prepare a solution of $0.5 \mathrm{M}$ thenoyltrifluoroacetone (TTA) in cyclohexane and protect it from light exposure. Always prepare this solution immediately prior to each experiment.

2. Add to the oxidized Pu solution $2 \mathrm{ml}$ of $0.1 \mathrm{M} \mathrm{CH}_{3} \mathrm{COONa}$ at $\mathrm{pH} 4.7$ and $2 \mathrm{ml}$ of $0.5 \mathrm{M}$ thenoyltrifluoroacetone (TTA) in cyclohexane. Wrap the bottle with aluminum foil to keep the reaction mixture in the dark, shake for 10 min. Separate the organic phase containing $\mathrm{Pu}(\mathrm{VI})$ with a pipette and transfer to a clean glass vial.

3. $\mathrm{Pu}(\mathrm{VI})$ to $\mathrm{Pu}(\mathrm{V})$ photoreduction

1. Leave the glass vial containing $\mathrm{Pu}(\mathrm{VI})-\mathrm{TTA}$ complex in cyclohexane at room light for $2 \mathrm{hr}$.

4. $\mathrm{Pu}(\mathrm{V})$ extraction

1. Add to the light-exposed solution $1 \mathrm{ml}$ of $0.1 \mathrm{M} \mathrm{CH}_{3} \mathrm{COONa}$ at $\mathrm{pH} 4.7$ and shake for 5 min. Remove aqueous phase, containing $\mathrm{Pu}(\mathrm{V})$. Determine the concentration of this source by liquid scintillation counting taking a $100 \mu \mathrm{l}$ aliquot. Note: Prepare $\mathrm{Pu}(\mathrm{V})$ solutions immediately prior to each experiment since the long-term stability of $\mathrm{Pu}$ in $+\mathrm{V}$ oxidation state is being questioned.

\section{Preparation of the Solutions Used in the Experiments}

1. Prepare buffered solutions

1. Make $10 \mathrm{mM}$ solution of MOPS (3-( $\mathrm{N}$-morpholino)propanesulfonic acid) buffer. Take $200 \mathrm{ml}$ of this solution and adjust to the desired $\mathrm{pH}$ by drop wise addition of $0.1 \mathrm{M} \mathrm{HCl}(\mathrm{pH} 6.5$ for use with $\mathrm{Pu}(\mathrm{IV})$ and $\mathrm{pH} 5.5$ for use with $\mathrm{Pu}(\mathrm{V}))$.

2. Prepare solutions for experiments with $\mathrm{Pu}(\mathrm{IV})$ 
1. Solution A

1. Dissolve Pu(IV) prepared at the step 1.1 in several milliliters of $10 \mathrm{mM}$ MOPS buffered solution at $\mathrm{pH}$ 6.5. Thoroughly wash the beaker with the same solution.

2. Bring the volume to $72 \mathrm{ml}$ with $10 \mathrm{mM}$ MOPS buffered solution at $\mathrm{pH} 6.5$. Check the $\mathrm{pH}$ and re-adjust to 6.5 with $0.1 \mathrm{M} \mathrm{NaOH}$. Transfer $72 \mathrm{ml}$ of this solution into a clean beaker — this is the (A) solution to be introduced into compartment $A$ of the diffusion cell.

2. Solution $B$

1. Take $72 \mathrm{ml}$ of $10 \mathrm{mM}$ MOPS buffered solution at $\mathrm{pH} 6.5$; add $0.75 \mathrm{ml}$ of $1 \mathrm{M} \mathrm{Na}_{2} \mathrm{SO}_{4}$. Check the pH, re-adjust to 6.5 if necessary. Transfer $72 \mathrm{ml}$ of this solution into a clean beaker — this is the « $\mathrm{B}$ » solution to be introduced into « $\mathrm{B}$ » compartment of the diffusion cell.

3. Prepare solutions with NOM

1. Weigh $1.4 \mathrm{mg}$ of freeze-dried fulvic or humic acid to a obtain concentration of $20 \mathrm{ppm}$ and dissolve it in the " $A$ » solution containing $\mathrm{Pu}(\mathrm{IV})$. Prepare this solution $24 \mathrm{hr}$ prior to experiment and to allow for equilibration.

3. Prepare solutions for experiments with $\mathrm{Pu}(\mathrm{V})$

1. Solution A

1. Dissolve $\mathrm{Pu}(\mathrm{V})$ obtained at the step 1.2 .4 in $72 \mathrm{ml}$ of $10 \mathrm{mM}$ MOPS buffered solution at pH 5.5; add $0.75 \mathrm{ml}$ of $1 \mathrm{M} \mathrm{NaNO}_{3}$. Check the $\mathrm{pH}$ and adjust to 5.5 if necessary. Transfer $72 \mathrm{ml}$ of this solution into a clean beaker. Prepare the solution with $\mathrm{Pu}(\mathrm{V})$ immediately prior to experiment.

2. Solution $B$

1. Take $72 \mathrm{ml}$ of $10 \mathrm{mM}$ MOPS buffered solution at $\mathrm{pH} 5.5$; add $0.75 \mathrm{ml}$ of $1 \mathrm{M} \mathrm{NaNO}_{3}$. Check the pH and adjust to 5.5 if necessary. Transfer $72 \mathrm{ml}$ of this solution into a clean beaker.

3. Prepare solutions with NOM

1. Weigh $1.4 \mathrm{mg}$ of freeze-dried fulvic or humic acid to obtain a concentration of $20 \mathrm{ppm}$ and dissolve in the A solution containing $\mathrm{Pu}(\mathrm{V})$. Leave the solution for $24 \mathrm{hr}$ to reach the steady state between $\mathrm{Pu}(\mathrm{IV})$ and $\mathrm{Pu}(\mathrm{V})$ species. Prior to diffusion experiment perform a liquid phase extraction to determine the fraction of $\mathrm{Pu}(\mathrm{V})$ as described in the Section 3.4.2.

\section{Laboratory Diffusion Experiments}

1. Prepare PAM gel

1. Wet a plastic tray with several milliliters of electrolyte (e.g., $10 \mathrm{mM} \mathrm{NaNO}_{3}$ ), place the PAM gel strip in and expand uniformly over the surface. Place cautiously a sharp punch of $2.7 \mathrm{~cm}$ in diameter on the gel surface. Avoid sliding the punch over the gel surface.

2. Use local focused lighting if necessary, it may help to visualize the transparent PAM gel. Press the punch firmly against gel surface and release once it is cut.

2. Assembly of the diffusion cell

1. Position the PAM gel disc with tweezers into the groove over the diffusion window in a smooth-faced manner. Turn the screw such that the two compartments of the diffusion cell hold together, interconnected via the PAM gel disc.

2. Mark A and B diffusion cell's compartments. Assemble the diffusion cell with the gel disc immediately prior to each experiment; do not allow the gel to dry.

3. Launching a diffusion experiment

1. Slowly pour the A and B solutions into the corresponding compartments. Make sure that both solutions are poured at the same speed in order to provide equal volume in each compartment at any time, otherwise the diffusive gel can be damaged.

2. Launch the timer once the solutions are in the cell. Place the miniature electric mixers over the diffusion cell. At this time the diffusion experiment is considered started.

4. Taking samples throughout diffusion experiment

1. Take samples of equal volume within regular time intervals from the $A$ and $B$ compartments simultaneously in order to keep volumes constant throughout the experiment.

1. Take a $1.00 \mathrm{ml}$ sample simultaneously in each compartment immediately at the beginning of the experiment to determine the initial Pu concentration in the A compartment.

2. Use a sampling time interval of $10 \mathrm{~min}$ in experiments without addition of NOM and $20 \mathrm{~min}$ to several $\mathrm{h}$ in experiments with humic acid. $2.00 \mathrm{ml}$ aliquots are sufficient to provide good sensitivity for alpha-spectrometric measurements.

2. Liquid phase extraction of $\mathrm{Pu}(\mathrm{IV})$ and $\mathrm{Pu}(\mathrm{V})$

1. At the end of the diffusion experiment take separately $4 \mathrm{ml}$ samples from the $A$ and the $B$ compartments into plastic test-tubes with leakproof caps. Acidify samples with $1 \mathrm{ml} 2 \mathrm{M} \mathrm{HCl}$.

2. Add $5 \mathrm{ml}$ of $0.5 \mathrm{M}$ bis-(2-ethyl hexyl) phosphoric acid (HDEHP) solution in cyclohexane and agitate test-tubes vigorously for 5 min. Leave samples to allow for phase separation. Remove the water phase containing $\mathrm{Pu}(\mathrm{V})$.

3. Back-extraction of $\mathrm{Pu}(\mathrm{IV})$ 
1. Back-extract $\mathrm{Pu}(\mathrm{IV})$ from the remaining organic phase with $5 \mathrm{ml}$ of $5 \%\left(\mathrm{NH}_{4}\right)_{2} \mathrm{C}_{2} \mathrm{O}_{4}$.

\section{Sample Treatment}

1. Spike samples with an internal standard

1. Spike samples to be analyzed with a yield tracer. Use a spike of $1.00 \mathrm{ml}$ of ${ }^{242} \mathrm{Pu}$ tracer of $25 \mathrm{mBq} \mathrm{ml}^{-1}$ activity concentration for alphaspectrometric measurements.

2. Oxidize samples' matrix

1. Evaporate samples to dryness on a hot plate with $2.00 \mathrm{ml}$ of concentrated $\mathrm{HNO}_{3}$.

\section{Radiochemical Separation of Pu}

1. Adjust Pu oxidation state

1. Dissolve dry samples from point 4.2 .1 in $5 \mathrm{ml} 8 \mathrm{M} \mathrm{HNO}_{3}$, add $20 \mathrm{mg} \mathrm{NaNO}_{2}$, heat samples at $70{ }^{\circ} \mathrm{C}$ during $10 \mathrm{~min}$. This step allows adjusting the oxidation state of Pu to +IV.

2. Solid phase extraction of $\mathrm{Pu}$

1. Wet a quaternary amine-based anion exchange resin column (such as TEVA) with $1.5 \mathrm{ml} 8 \mathrm{M} \mathrm{HNO}_{3}$. Use micro-columns made of $1 \mathrm{ml}$ pipette tip with $100 \mathrm{mg}$ of the resin conditioned with $1.5 \mathrm{ml} 8 \mathrm{M} \mathrm{HNO}_{3}$.

2. Pass the solution of point 5.1.1 through the resin column with flow rate of about $1 \mathrm{ml} \mathrm{min}{ }^{-1}$. Rinse the sample beaker with $2 \mathrm{ml} 8 \mathrm{M}$ $\mathrm{HNO}_{3}$ three times and transfer washouts to resin columns.

3. Elute $\mathrm{Pu}$

1. Wash columns with $3 \mathrm{ml} 9 \mathrm{M} \mathrm{HCl}$. Elute Pu with $3 \mathrm{ml}$ solution $9 \mathrm{M} \mathrm{HCl} / 0.1 \mathrm{M} \mathrm{HI}$. Evaporate eluates on the hot plate. Treat with $2 \mathrm{ml}$ concentrated $\mathrm{HNO}_{3}$, evaporate to dryness. Repeat if necessary until the brown iodine color disappears.

2. Determine Pu concentration in the samples by any available method.

Note. For the concentrations range of ${ }^{239} \mathrm{Pu}$ used in this protocol alpha-spectrometry provides a good sensitivity. Prepare sources for alpha-spectrometric counting by electroplating on stainless steel discs ${ }^{14}$. Count sources on PIPS detector $\left(450 \mathrm{~mm}^{2}\right)$ in a spectrometer

\section{Analysis of the Data}

1. Plot diffused Pu versus time

1. Plot the activity of $\mathrm{Pu}(\mathrm{mBq})$ accumulated in the $\mathrm{B}$ compartment versus time (min). Correct for volume of the sample taken out during the diffusion experiment: activity of accumulated $\mathrm{Pu}(\mathrm{mBq})$ at time $\mathrm{t}$ is equal to the concentration $\left(\mathrm{mBq} \mathrm{ml}^{-1}\right)$ determined in the sample multiplied by the volume of the solution $(\mathrm{ml})$ in the compartment $\mathrm{B}$ at the moment of sampling (see example of the spreadsheet Figure 2).

2. To plot on the same graph data from several experiments with different Pu concentrations, use concentrations normalized to the initia Pu concentration of compartment $A$.

2. Calculate diffusion coefficient

1. Calculate diffusion coefficient $\mathrm{D}\left(\mathrm{cm}^{2} \mathrm{sec}^{-1}\right)$ of $\mathrm{Pu}$ species for each experiment ${ }^{10}$. Use equation (1):

$D=\frac{\Delta g}{C \times S} \times \frac{\Delta A}{\Delta t}$

where $\Delta g$ is the diffusion gel thickness $(\mathrm{cm}), C$ the initial Pu concentration $\left(\mathrm{mBq} \mathrm{ml}^{-1}\right), S$ the diffusion area $\left(\mathrm{cm}^{2}\right)$, and $A$ the activity $(\mathrm{mBq})$ of Pu species diffused in compartment $\mathrm{B}$ at the time $t(\mathrm{sec}) . \Delta A / \Delta t$ is the slope of the linear plot of Pu diffused into the $\mathrm{B}$ compartment versus time.

\section{Bioavailability Studies of Pu in Natural Freshwaters}

1. Prepare DGT samplers

1. Wet a plastic tray with several milliliters of electrolyte (e.g., $10 \mathrm{mM} \mathrm{NaNO}_{3}$ ), place the bottom plate (see Figure 3) of the DGT sampler. Use local lighting if necessary, it may help to visualize transparent gels.

2. Position a $6 \mathrm{~cm} \times 22 \mathrm{~cm}$ Chelex resin gel strip and expand uniformly over the plate's surface. Place on the top of the resin gel layer a 6 $\mathrm{cm} \times 22 \mathrm{~cm}$ PAM diffusive gel strip and expand uniformly over the surface. Make sure that gels are not sliding and are positioned in a smooth-faced manner.

3. Cover the diffusive gel layer with a $6 \mathrm{~cm} \times 22 \mathrm{~cm}$ piece of a filter membrane. Place the cover frame of the DGT sampler (see Figure 3) over the filter membrane and close the assembly slightly pressing the frame on the edges.

4. Cut the extending gel parts off with a sharp lancet, open and realign gel layers if necessary until a smooth plate surface is obtained. Fix the assembly with screws.

5. Wet the DGT samplers with several milliliters of electrolyte (e.g., $10 \mathrm{mM} \mathrm{NaNO}_{3}$ ). Store wet in a sealed plastic bag up to several weeks at $4-5^{\circ} \mathrm{C}$. 
1. Take the DGT sampler out of the plastic bag. Fix DGT samplers in the holder as shown on the Figure 4.

2. Deploy DGTs in the body of water either suspending them on a strong rope or installing on a stable vertical support in a way to provide a constant tangential water flow along the surface of the DGT. Deploy DGT devices in the freshwaters for two to three weeks in order to accumulate the $\mathrm{Pu}$ at a concentration sufficient for measurements.

3. Treatment of retrieved DGTs

1. Retrieve DGTs from the water. Unscrew the assembly, take out filter membrane and discard. Take out the upper gel layer (PAM diffusive gel) and discard.

2. Transfer the resin gel into a glass beaker containing $20 \mathrm{ml} 8 \mathrm{M} \mathrm{HNO}_{3}$ and spike samples to be analyzed with a yield tracer. Use a spike of $1.00 \mathrm{ml}^{242} \mathrm{Pu}$ tracer of $0.25 \mathrm{mBq} \mathrm{ml}^{-1}\left(1.7 \mathrm{pg} \mathrm{ml}^{-1}\right)$ activity concentration for AMS measurements. After having well agitated, leave samples $\mathrm{O} / \mathrm{N}$ for Pu elution.

4. Condition DGT eluates

1. Filter the solutions from the resin gel samples; rinse the remaining resin gels with $5 \mathrm{ml} 8 \mathrm{M} \mathrm{HNO}_{3}$ and combine washouts with samples. Add $20 \mathrm{mg} \mathrm{NaNO}$ to each sample, heat the solutions at $70{ }^{\circ} \mathrm{C}$ during $10 \mathrm{~min}$. This step allows adjusting the oxidation state of $\mathrm{Pu}$ to + IV.

5. Solid phase extraction of $\mathrm{Pu}$

1. Wet a quaternary amine-based anion exchange resin cartridge with $10 \mathrm{ml} 8 \mathrm{M} \mathrm{HNO}_{3}$. Pass the solutions of point 7.4 .1 through the exchange resin cartridge with flow rate of about $1 \mathrm{ml} \mathrm{min}^{-1}$. Rinse the sample beaker with $5 \mathrm{ml} 8 \mathrm{M} \mathrm{HNO}_{3}$ three times and transfer the washouts to exchange resin cartridge.

6. Elute Pu

1. Wash cartridges with $10 \mathrm{ml} 9 \mathrm{M} \mathrm{HCL}$. Elute Pu with $15 \mathrm{ml}$ solution $9 \mathrm{M} \mathrm{HCl} / 0.1 \mathrm{M} \mathrm{HI}$. Evaporate eluate on a hot plate. Treat with $2 \mathrm{ml}$ concentrated $\mathrm{HNO}_{3}$, evaporate to dryness. Repeat if necessary until the brown iodine color has completely disappeared.

2. Repeat radiochemical separation of Pu one to two more times if higher purification is required - depending on the performance of Pu detecting system. Perform the second and the third separations on micro-columns made of $1 \mathrm{ml}$ pipette tip with $100 \mathrm{mg}$ of exchange resin conditioned with $1.5 \mathrm{ml} 8 \mathrm{M} \mathrm{HNO}_{3}$.

3. Determine Pu concentration in the samples. Use the mass-spectrometry techniques to measure ${ }^{239} \mathrm{Pu}$ because of the very low level of plutonium in the pristine environment.

Note: In this work, use the AMS facility tuned for analysis of actinides at the Laboratory of lon Beam Physics at the Swiss Federal Institute of Technology in Zurich.

\section{Analysis of the Data}

1. Calculate the concentration $\left(C_{D G T}\right.$ in $\left.\mu \mathrm{Bq} \mathrm{ml} l^{-1}\right)$ of bioavailable (labile) Pu species in the bulk water from the amount of Pu accumulated by DGT during the deployment period. Use equation (2):

$C(D G T)=\frac{A \times \Delta g}{D \times S \times t}$

where $A$ is the activity $(\mu \mathrm{Bq})$ of $\mathrm{Pu}$ accumulated in the binding phase, $\Delta g$ the diffusion layer (gel + filter membrane) thickness (cm), $D$ the diffusion coefficient of Pu in the PAM gel $\left(\mathrm{cm}^{2} \mathrm{sec}^{-1}\right), S$ the diffusion area $\left(\mathrm{cm}^{2}\right)$, and $t$ the duration of deployment $(\mathrm{sec})$.

2. Compare $C_{D G T}$ of Pu determined by DGTs with total Pu concentration in the bulk water, as well as with other available speciation data.

\section{Radiochemical Separation for the Determination of Total Pu in the Bulk Water}

1. Condition water sample

1. Pump water from the studied body of water through a $45 \mu \mathrm{m}$ membrane filter into a plastic recipient. Work with samples of $10 \mathrm{to} 50 \mathrm{~L}$ for AMS measurements. Acidify the water to $\mathrm{pH} 2$ with $\mathrm{HNO}_{3}$ immediately after sampling at the sampling site prior to transporting to the laboratory.

2. Precipitate Pu on iron hydroxides

1. In the laboratory introduce an overhead stirrer into the recipient. Spike the sample with Pu yield tracer. Use a spike of $1.00 \mathrm{ml}$ of ${ }^{242} \mathrm{Pu}$ tracer of $0.25 \mathrm{mBq} \mathrm{ml}^{-1}\left(1.7 \mathrm{pg} \mathrm{ml}^{-1}\right)$ activity concentration for AMS measurements.

2. Add $\mathrm{FeCl}_{3} \cdot 6 \mathrm{H}_{2} \mathrm{O}$ taking about $0.25 \mathrm{~g}$ per $10 \mathrm{~L}$ sample. After having agitated for 30 min, precipitate iron hydroxides with $\mathrm{NH}_{4} \mathrm{OH}$ at $\mathrm{pH} 8$.

3. Second precipitation of Pu on iron hydroxides

1. Decant the supernatant from water sample from point 9.2.2. Recover the precipitate of iron hydroxides into a $2 \mathrm{~L}$ glass beaker, rinse the recipient with deionized water and combine the washouts with the sample.

2. Dissolve the precipitate in $\sim 100 \mathrm{ml} 5 \mathrm{M} \mathrm{HCl}$, heat to $90^{\circ} \mathrm{C}$ to decompose carbonates. Filter if necessary when the solution is cooled down. Re-precipitate iron hydroxides with $\mathrm{NH}_{4} \mathrm{OH}$ at $\mathrm{pH} 8$.

4. Condition iron hydroxides for analysis

1. Decant the supernatant from the sample from point 9.3.2. Recover the precipitate of iron hydroxide into a centrifugation vessel. Centrifuge, discard the supernatant. Wash the precipitate with deionized water. Repeat 2-3 times.

2. Dissolve the precipitate in $10 \mathrm{ml} 8 \mathrm{M} \mathrm{HNO}_{3}$, submit to radiochemical separation of $\mathrm{Pu}$ as described previously in the sections 7.4-7.6. 


\section{Prepare Samples for AMS Measurements}

1. Precipitate Pu on iron hydroxides

1. After radiochemical separation, dissolve the final sample in $0.5 \mathrm{ml} 1 \mathrm{M} \mathrm{HCl}$, transfer the sample with a plastic pipette into a $2.5 \mathrm{ml}$ glass vial. Rinse the sample beaker twice with $0.5 \mathrm{ml} 1 \mathrm{M} \mathrm{HCl}$, transfer washouts to the same vial.

2. Add $0.5 \mathrm{ml}$ of $2 \mathrm{mg} \mathrm{m}^{-1} \mathrm{Fe}^{3+}$ stock solution to provide $1 \mathrm{mg}$ of iron. Precipitate iron hydroxides adding few drops of concentrated $\mathrm{NH}_{4} \mathrm{OH}$. Centrifuge and decant the supernatant.

3. Wash the precipitate with deionized water, centrifuge and decant the supernatant. Dry the precipitate on the hot plate at $90{ }^{\circ} \mathrm{C}$.

2. Prepare target for AMS measurements

1. Bake the hydroxides precipitate from point 10.1 .3 in a furnace for $2-3 \mathrm{hr}$ at $650{ }^{\circ} \mathrm{C}$. Thoroughly mix with $3-4 \mathrm{mg}$ of niobium metal powder and press into a Ti target holder for AMS measurements.

Note: We measured the samples with the compact (0.6 MV) AMS system "TANDY" at the Swiss Federal Institute of Technology (ETH Zurich) tuned for measurements of actinides ${ }^{15,16}$.

Representative Results

\section{Diffusion experiments}

Plotting the activities of ${ }^{239} \mathrm{Pu}$ diffused into the B compartment of the diffusion cell versus time gives a visual representation of the flux of the ${ }^{239} \mathrm{Pu}$ species diffusing through the PAM gel. Diffusion coefficients calculated from these plots according to equation 1 provide an additional means to compare mobility of different ${ }^{239} \mathrm{Pu}$ redox species in various chemical environments (Figure 2). Figure 5 illustrates the diffusion experiments with $\mathrm{Pu}(\mathrm{IV})$ and $\mathrm{Pu}(\mathrm{IV})-\mathrm{Pu}(\mathrm{V})$ mixed species, respectively, in the MOPS buffer and in presence of $20 \mathrm{ppm}$ of HA. A comparison of these plots shows that $\mathrm{Pu}(\mathrm{V})$ is significantly more mobile than $\mathrm{Pu}(\mathrm{IV})$. This is particularly valid for $\mathrm{Pu}(\mathrm{IV})$ and $\mathrm{Pu}(\mathrm{V})$ when $\mathrm{HA}(\mathrm{MW} 5-40 \mathrm{kDa}$ in our experiments, characterized in the SI by Cusnir et al. $)^{10}$ is added as complexing molecules. Pu(V) source solution prepared according to the protocol described in this paper contains predominately $\mathrm{Pu}(\mathrm{V})$ species. Liquid phase extraction with HDEHP at the end of the diffusion experiment in the MOPS buffered solution found $80 \% \pm 10 \%$ of $\mathrm{Pu}(\mathrm{V})$. The chemical yield of this extraction is $80 \%$. The solution with $\mathrm{Pu}(\mathrm{V})$ in presence of $20 \mathrm{ppm}$ of $\mathrm{HA}$ was equilibrated during $24 \mathrm{hr}$ and $\mathrm{Pu}(\mathrm{V})$ fraction in this model solution was $35 \% \pm 10 \%$.

\section{Studies on Pu bioavailability in natural freshwaters}

Several DGT devices constructed in our laboratory were successfully exposed for periods of two to three weeks in a karst spring of the Swiss Jura Mountains. This is a mineral spring with the $\mathrm{pH}$ of the water in the range of $6.5-7.5$, conductivity above $400 \mu \mathrm{S} \mathrm{cm}^{-1}$ and saturated with oxygen. These experiments demonstrated good applicability and robustness of the gel assemblies with no trace of biofouling, possibly also because of the low temperature of the spring $\left(7^{\circ} \mathrm{C}\right)$. DGTs retrieved after the deployments were well preserved, with gel layers intact, conserving the initial form and visual appearance. Pu accumulated by DGTs was analyzed by AMS. AMS provides considerable advantages over other analytical techniques: it is highly sensitive (down to sub-fg levels), and requires much lower initial sample amount than alphaspectrometry or ICP-MS techniques. In addition, molecular isobaric interferences, such as the uranium hydride $\left({ }^{238} \mathrm{U}-\mathrm{H}\right)$, or other molecules are efficiently suppressed during the AMS measurement and do not interfere with the ${ }^{239} \mathrm{Pu}$ detection. For some technical reasons (most probably a contamination with ${ }^{239} \mathrm{Pu}$ during chemical separations), we were not able to use the data for ${ }^{239} \mathrm{Pu}$ for the first applications of DGTs in the field. Nevertheless, the ${ }^{240} \mathrm{Pu}$ results were unbiased. Thus, we calculated the ${ }^{239} \mathrm{Pu}$ content from the measured ${ }^{240} \mathrm{Pu}$, taking 0.18 as ${ }^{240} \mathrm{Pu} /{ }^{239} \mathrm{Pu}$ atomic ratio for fallout plutonium. The results are summarized in Table 1.

${ }^{239} \mathrm{Pu}$ concentrations measured in bulk water samples are similar to concentrations previously reported for this aquifer $\left(1-7 \mu \mathrm{Bq} \mathrm{L}^{-1}\right)^{11}$.

Furthermore, ${ }^{239} \mathrm{Pu}$ concentrations calculated from DGT measurements are similar within the uncertainties of the measurement. Since DGTs accumulate only free and labile Pu species, one can estimate the fraction of bioavailable Pu in this water. Data given in Table 1 indicate that all the ${ }^{239} \mathrm{Pu}$ species present in the bulk water are found in a bioavailable form. This is an interesting result in the light of previous findings ${ }^{11}$, which have revealed the predominant accumulation of ${ }^{239+240} \mathrm{Pu}$ in the intracellular fraction of the aquatic mosses growing in the spring compared to ${ }^{241} \mathrm{Am}$ and ${ }^{90} \mathrm{Sr}$. The authors ${ }^{11}$ suggested that the enhanced mobility of $\mathrm{Pu}$ in this natural aquifer was due to formation of a soluble carbonate $\mathrm{Pu}$ complex, possibly as a $\mathrm{Pu}(\mathrm{V})$ plutonyl form, similar to naturally occurring uranyl-carbonate complex. Water of the Venoge spring is hard water, with high carbonate concentration and very low NOM content (about $1 \mathrm{ppm}$ ). 


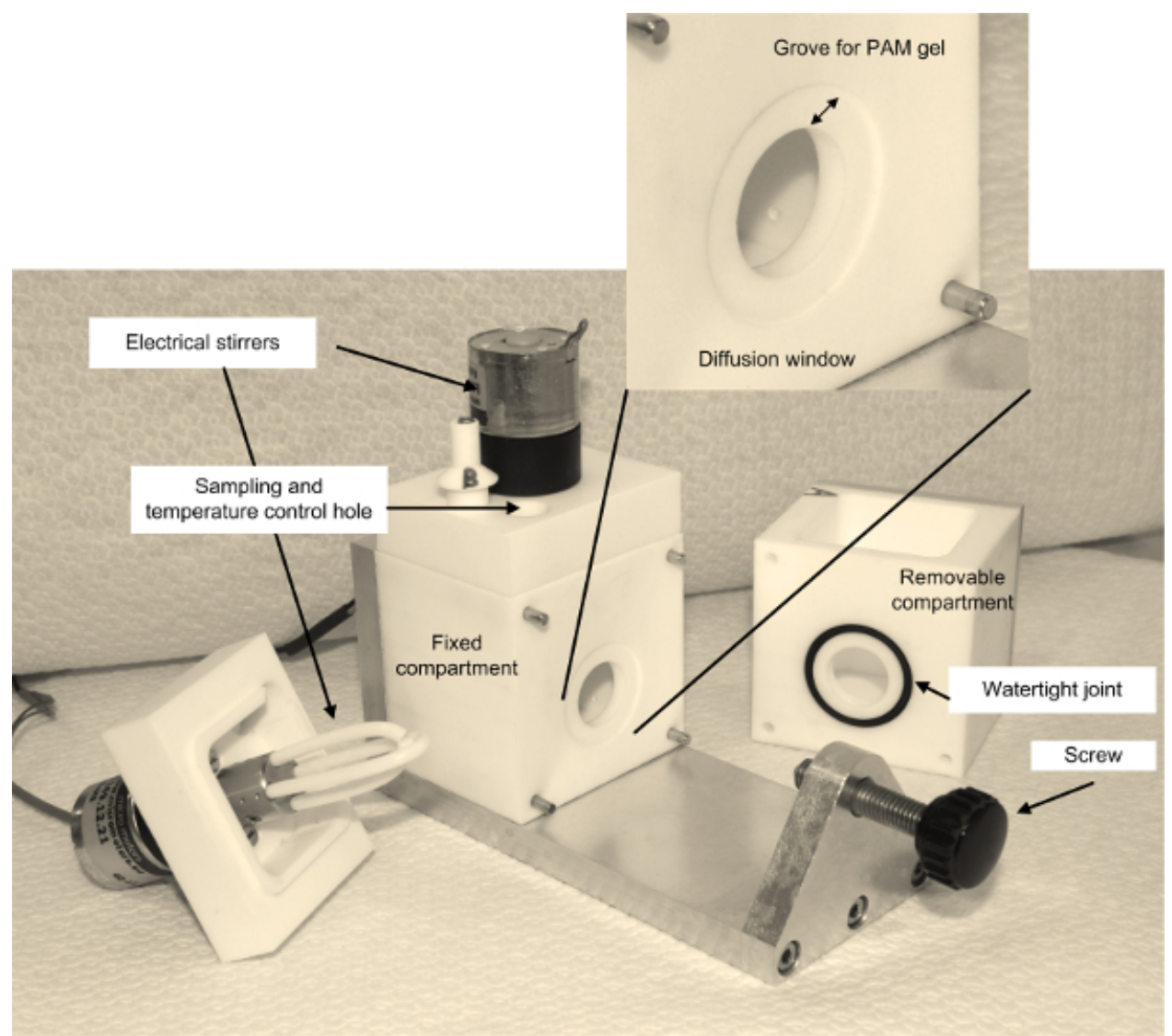

Figure 1. Diffusion cell used for experiments on Pu diffusion through the PAM gel. The groove thickness $0.5 \mathrm{~cm}$, the groove depth 0.39 $\mathrm{mm}$. Please click here to view a larger version of this figure.

\begin{tabular}{|c|c|c|c|c|c|c|c|c|c|c|}
\hline & A & & B & C & $\mathrm{D}$ & $\mathrm{E}$ & $\mathrm{F}$ & $\mathrm{G}$ & $\mathrm{H}$ & $T$ \\
\hline 1 & Nr. & Number & f counts Pu-239 & Number of counts $\mathrm{Pu}-242$ & C Pu-239, $\mathrm{mBq} / \mathrm{ml}$ & $\mathrm{CPu}-242, \mathrm{mBq} / \mathrm{ml}$ & Pu-239 diffused, $\mathrm{mBq}$ & $T, \min$ & $v, \mathrm{ml}$ & \\
\hline 2 & 1 & & 76 & 6115 & 0,18 & $\left.=\left(\left(B 2^{*} E 2\right) / C 2\right)\right) / 2$ & 13,06 & 10 & 72 & \\
\hline 3 & 2 & & 95 & 6022 & 0,23 & $2 \mathrm{ml}$ - eamole yp & 16,12 & 20 & 70 & \\
\hline 4 & 3 & & 188 & 6194 & 0,44 & 29,2 & $30,13^{*}$ & 30 & 68 & \\
\hline 5 & & & & & & & & $=\mathrm{D} \cdot \mathrm{H}$ & & \\
\hline 6 & & 120,00 & $\mathrm{~A}(\mathrm{Pu}-23$ & 39) diffused = f (tim & & & & & & \\
\hline 7 & & 120,00 & & $y=0,9074 x+$ & 2,057 & $\Delta \mathrm{g}=0.039 \mathrm{~cm}$ & & & & \\
\hline 8 & हू & 100,00 & & $R^{2}=0,9 S C$ & & $P_{u}(\mathrm{IV}) C_{D}=113.55 \mathrm{n}$ & $\mathrm{mBq} / \mathrm{cm}^{3}$ & & & \\
\hline 9 & ஜ: & 80,00 & & & & $S=2.27 \mathrm{~cm}^{2}$ & & & & \\
\hline 10 & $\stackrel{3}{3}$ & 60,00 & & & & $\mathrm{pH}=6.50$ & & & & \\
\hline 11 & 임 & 8000 & & & & MOPS buffer $10 \mathrm{mN}$ & & & & \\
\hline 12 & 峞 & & & & & & & & & \\
\hline 13 & & 20,00 & & & & $D=\left(\Delta B / C_{D} * S\right)^{*}(\Delta A / \Delta t$ & & & & \\
\hline 14 & & 0,00 & & & $\neg$ & & & & & \\
\hline 15 & & d & 20 & $400_{\text {nime, min }} 60$ & 120 & $D=(10.039 \mathrm{~cm} /(113$. & $\left..55 \mathrm{mBq} / \mathrm{cm}^{3}=2.27 \mathrm{~cm}^{2}\right]$ & $1)^{*} 0.907$ & $74 \mathrm{mBc}$ & ) 60 \\
\hline 16 & & & & & & & & & & \\
\hline
\end{tabular}

Figure 2. Snapshot of the Excel Worksheet used for calculations of the diffusion coefficient. Please click here to view a larger version of this figure. 


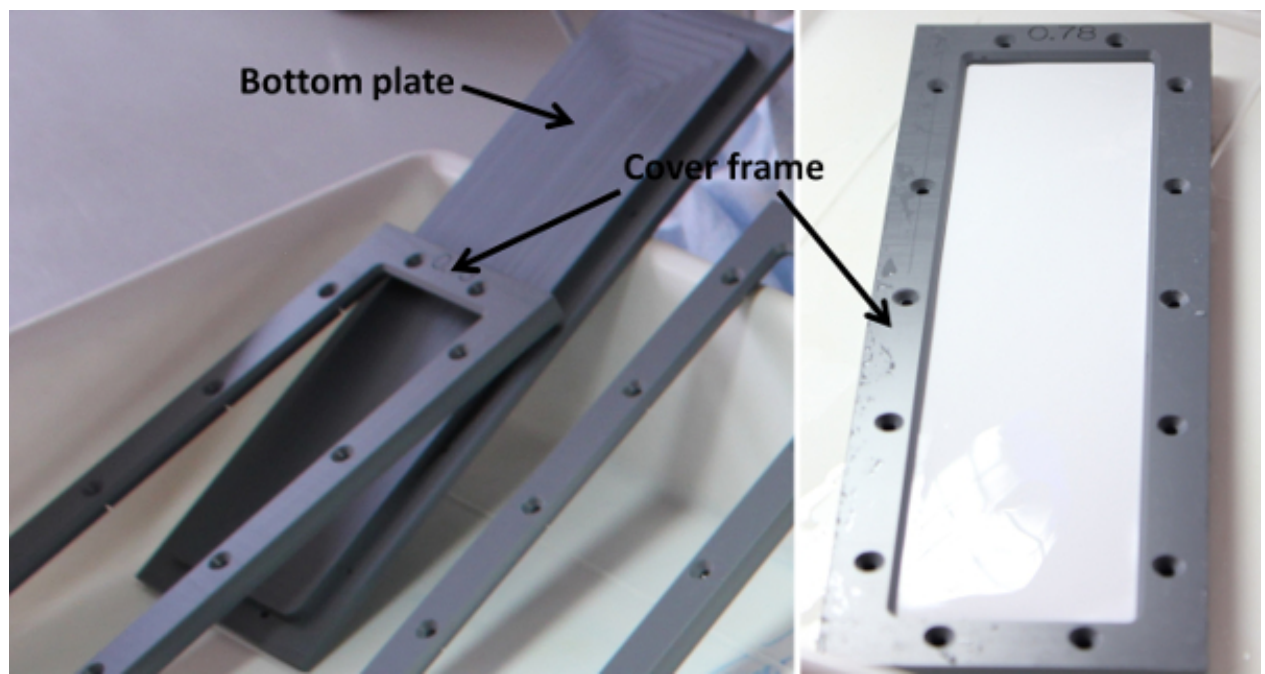

Figure 3. Large-surface DGT device for environmental Pu speciation measurements. Parts of the DGT device - the bottom plate and the cover frame - depicted on the left, the assembly with crew holes on the right. Please click here to view a larger version of this figure.
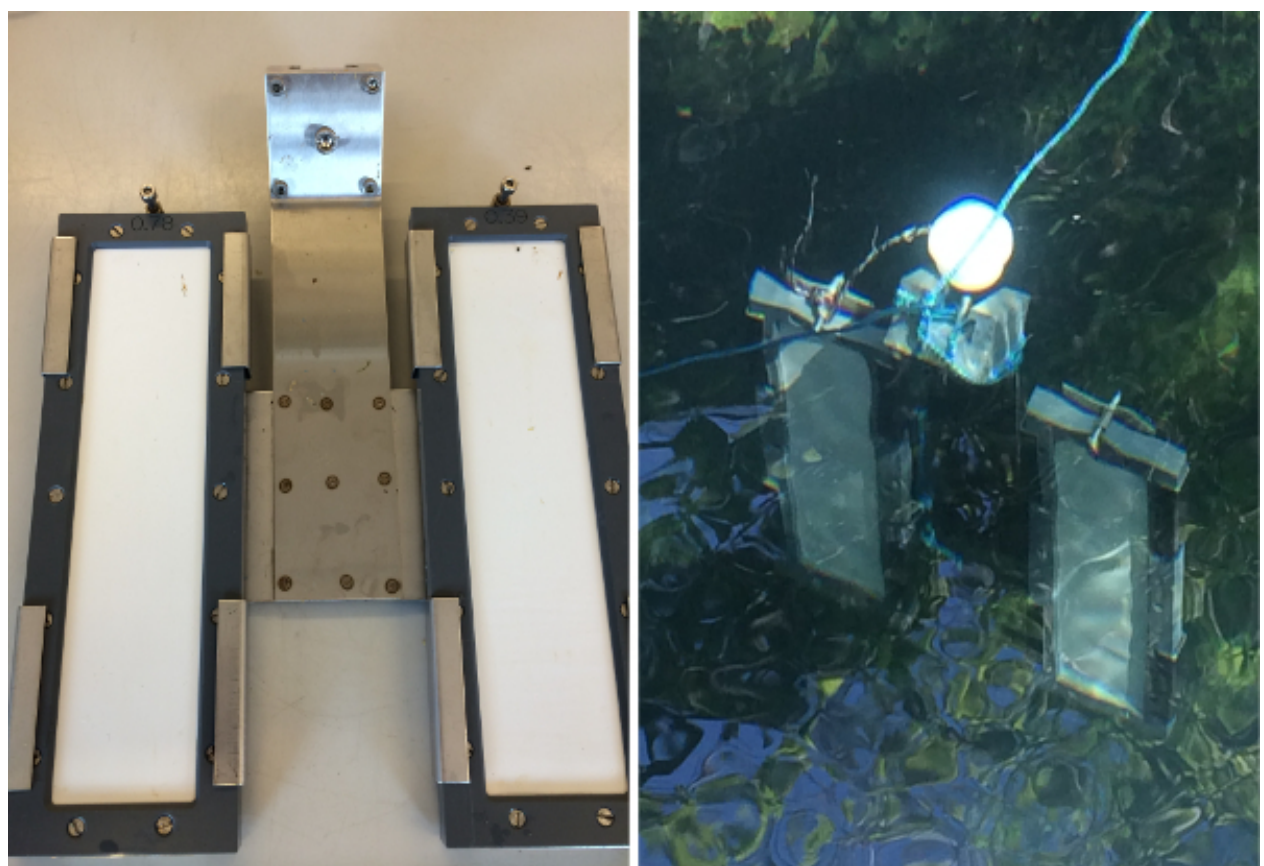

Figure 4. DGT sampler devices fixed in the holder (left) exposed in the Venoge spring (right) for Pu bioavailability measurements. Please click here to view a larger version of this figure. 


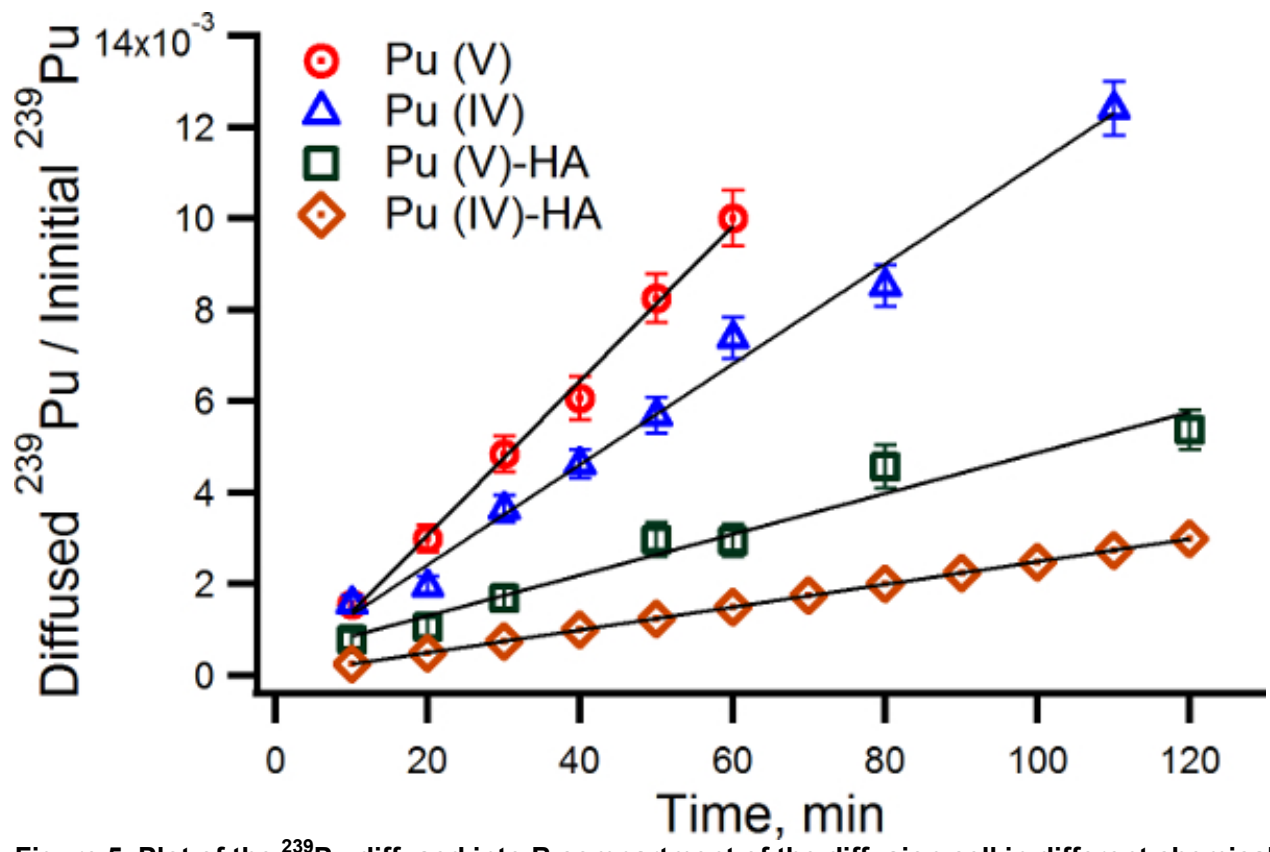

Figure 5. Plot of the ${ }^{239} \mathrm{Pu}$ diffused into $\mathrm{B}$ compartment of the diffusion cell in different chemical environments. Experimental data points are given for ${ }^{239} \mathrm{Pu}(\mathrm{IV})$ and ${ }^{239} \mathrm{Pu}(\mathrm{V})$, respectively, in MOPS buffer as well as for ${ }^{239} \mathrm{Pu}(\mathrm{IV}){ }^{239} \mathrm{Pu}(\mathrm{V}) \mathrm{mixed}$ species $(35 \% \pm 10 \%$ of $\mathrm{Pu}(\mathrm{V}))$ in the presence of HA. The line shown for ${ }^{239} \mathrm{Pu}(\mathrm{IV})-\mathrm{HA}$ has been calculated using a diffusion coefficient of $0.50 \times 10^{-6} \mathrm{~cm}^{2} \mathrm{sec}^{-1}$ determined previously ${ }^{10}$. Diffusion coefficients calculated from equation 1 are: $\mathrm{Pu}(\mathrm{IV})$ in MOPS buffer $-2.29 \times 10^{-6} \mathrm{~cm}^{2} \mathrm{sec}^{-1}$, Pu(V) in MOPS buffer $3.50 \times 10^{-6} \mathrm{~cm}^{2} \mathrm{sec}^{-1}, \mathrm{Pu}(\mathrm{IV})-\mathrm{Pu}(\mathrm{V})$ with $\mathrm{HA}-0.92 \times 10^{-6} \mathrm{~cm}^{2} \mathrm{sec}^{-1}$. From top to bottom: Pu(V) in MOPS buffer (red open circle), Pu(IV) in the MOPS buffer (blue open triangles), Pu(IV) - Pu(V) in presence of 20 ppm of HA (green open squares), $\mathrm{Pu}(\mathrm{IV})$ in presence of 20 ppm of HA (brown open diamonds). Please click here to view a larger version of this figure.

\begin{tabular}{|l|l|l|}
\hline Sample type & Number of measurements & ${ }^{239} \mathbf{P u}$ concentration, $\boldsymbol{\mu B q} \mathrm{L}^{-1}$ \\
\hline Bulk water & 2 & $1.9 \pm 0.55$ \\
\hline DGT $0.39 \mathrm{~mm}$ & 2 & $1.74 \pm 0.9$ \\
\hline DGT $0.78 \mathrm{~mm}$ & 1 & $1.79 \pm 0.9$ \\
\hline
\end{tabular}

Table 1. Representative results for ${ }^{239} \mathrm{Pu}$ measurements by AMS in the bulk water and DGT samplers. ${ }^{239} \mathrm{Pu}$ in the bulk water was co-precipitated from $20 \mathrm{~L}$ of water with iron hydroxides, extracted on the actinide-specific exchange resin and measured by AMS. ${ }^{239} \mathrm{Pu}$ concentrations for DGT measurements calculated using equation 2 and diffusion coefficient for $\mathrm{Pu}(\mathrm{IV})$. Uncertainties for $k=2$; $\mathrm{u}(95)$.

\section{Discussion}

The DGT methodology described here for experiments with Pu using a diffusion cell provides a reliable approach for various studies on Pu redox species and their interactions with organic molecules, colloidal particles and simulated environmental systems. Further applications of DGTs for environmental measurements of Pu will contribute to our understanding of the bioavailability and the fate of this radionuclide in aquatic ecosystems.

\section{Laboratory diffusion experiments}

In order to perform a successful diffusion experiment with meaningful conclusions on Pu mobility and interactions regarding a specific chemical environment, well defined and controllable conditions must be provided. The adjustment of Pu oxidation states prior to experiment is essential to simplify the data interpretation as well as to simulate various biogeochemical behaviors of Pu redox species. The sensitivity of Pu species to $\mathrm{pH}$ variations makes buffering the solutions a must. Particular attention should be drawn to the diffusion cell features and setup: the use of nonsorbing Teflon polymer material avoids adsorption on the cell walls and allows a robust leakproof assembly, preventing loss of Pu from diffusing solutions during the experiment.

The initial Pu concentration to be introduced into the A compartment, as well as the sampling interval and the volume of each sample taken during the diffusion experiment depend on the analytical method available in the laboratory. Any available analytical method can be used for determination of Pu concentration in the samples from the diffusion cell, however this choice is tightly bound to the initial activity of Pu taken for the experiment. $10 \mathrm{~Bq}$ of ${ }^{239} \mathrm{Pu}$ as recommended in this protocol (giving $100-140 \mathrm{mBq} \mathrm{ml}^{-1}$ or $\sim 2 \times 10^{-13} \mathrm{~mol} \mathrm{ml}^{-1}$ ) are sufficient to provide enough sensitivity for measurements by alpha-spectrometry and generally do not pose particular problems for radiation protection regulations. The initial concentration of Pu can be reduced if other, more sensitive, analytical techniques are available for Pu determination (e.g., mass-spectrometry). Sampling interval can be selected for each diffusion experiment, depending on Pu initial concentration, and the expected rate of diffusion through the PAM gel. In spite of the fact that the aliquots from diffusion experiments do not contain radionuclides other than $\mathrm{Pu}$, the presence of mineral 
salts and of the MOPS buffer can interfere with analytical procedure, reducing the efficiency and the precision of quantitative analysis. Therefore it is preferable to perform a chemical separation of Pu on these samples.

The diffusion cell provides the best approach to study diffusion in the PAM gel since the gel is exposed directly to a well stirred solution. Thus, the effects of the diffusive boundary layer (DBL) at the gel surface are considered negligible. Good stirring of the solutions during a diffusion experiment is essential, allowing for minimization of the DBL effects. In the same time, one should proceed carefully in order to not disrupt the PAM gel.

\section{Studies of Pu bioavailability in natural freshwaters}

The results produced by this protocol show that measuring plutonium with DGT devices provides an efficient tool to study the bioavailability of plutonium in freshwater. DGT measurements yield time-average concentration of free and labile species, the two most important forms for biological uptake by living organisms. In addition, the kinetics of the interaction of Pu with organic matter can be investigated using gels of different thickness. The time necessary for Pu-NOM species to diffuse through the gel will allow for the most labile complexes to dissociate. DGT measurements can be complemented by ultrafiltration techniques, which yield the percentage of Pu colloidal species above a given size (e.g., 8 $\mathrm{kDa}$ ). Pu colloidal species are usually considered as non-bioavailable species and are part of the Pu fraction not measurable using DGT.

At this point, the DGT devices were deployed only in freshwater of a karst spring of the Swiss Jura Mountains. Low environmental concentrations of Pu require a long-term deployment of DGT devices, which can encounter potential drawbacks. Biofouling of the DGT surface represents a significant drawback, increasing the DBL thickness and thus limiting the flux of Pu through the PAM gel. Binding phase of the DGTs exposed in marine waters or waters of high mineralization may be rapidly saturated with other trace metals, misrepresenting the data for accumulation of $\mathrm{Pu}$. Determination of trace levels of environmental Pu requires a thorough radiochemical separation and very sensitive analytical methods. AMS measurements applied in this protocol are not widely available, but can be replaced by other mass-spectrometry techniques. However, a rigorous radiochemical separation is necessary to eliminate the isobaric interference ${ }^{238} \mathrm{U}-\mathrm{H}$ from naturally occurring uranium.

Equation 2 shows that the size of the DGT device is an essential parameter that can be tuned to increase the quantity of accumulated Pu during a given deployment time. Commercial gel strips are available only with a maximum surface of $6 \mathrm{~cm} \times 22 \mathrm{~cm}$. Therefore, the window of the DGT sampler has been increased to $105 \mathrm{~cm}^{2}(5 \mathrm{~cm} \times 21 \mathrm{~cm})$, making possible to accumulate enough of Pu species for relatively short deployment times. The assembly of such a DGT sampler requires precision and particular consideration of the PAM gel sheet properties while manipulating. It is of fundamental importance to assemble gel layers into a smooth-faced uniform "sandwich" in order to provide a homogeneous flux of Pu species from the bulk water through the diffusive gel. Good water flow at the DGT surface is also an important parameter, yet it is mostly determined by flow conditions in the aquifer. It is recommended to place DGT devices for Pu measurements at about $45^{\circ}$ towards the direction of water flow in order to provide a steady water supply and minimize the effects of the DBL.

Diffusion coefficient employed in the equation 2 must be corrected if the temperature in the studied body of water is different from the temperature at which the diffusion coefficient was determined. Temperature effects on diffusion coefficients are given by Stokes-Einstein equation (equation 3):

$\frac{D 1 \eta 1}{T 1}=\frac{D 2 \eta 2}{T 2}$

where $D_{1}$ and $D_{2}$ are diffusion coefficients $\left(\mathrm{cm}^{2} \sec ^{-1}\right), \eta_{1}$ and $\eta_{2}$ are viscosities $(\mathrm{mPa} \mathrm{sec})$ of water at temperatures $T_{1}$ and $T_{2}(K)$ respectively.

Currently, there is no method to investigate Pu speciation in pristine environment, except for thermodynamic calculations based on, e.g., $\mathrm{pH}$ and redox parameters. These parameters are only available for macro-components, such as carbonates, iron or manganese cations. Thus, Pu speciation is derived from these measurable species but does not represent a "real" measurement. Here we think that the diffusion in thin PAM gel film technique as presented in this paper is an important step in the resolution of the Pu speciation problem because it allows measuring in situ free and labile species and, possibly, evidencing plutonyl species. Although only a few DGT measurements of the environmental Pu in freshwaters have been undertaken so far, the obtained results are encouraging for further applications of the DGT technique for Pu speciation and bioavailability studies. Deployment of DGTs in organic-rich waters will potentially yield important information on Pu mobility and interactions in presence of NOM molecules. Interesting results should be expected from DGT measurements in contaminated marine environments, such as the coastal seas around the Sellafield nuclear reprocessing plant and the damaged Fukushima Daiichi nuclear power plant.

\section{Disclosures}

The authors have nothing to disclose.

\section{Acknowledgements}

This work was funded by the Swiss National Science Foundation (grant $n^{\circ} 200021-140230$ ) and by the Swiss Federal Office of Public Health (PF and PS). We thank the Swiss Federal Office of Public Health for providing financial support for the open-access publication of this paper.

\section{References}

1. Kaplan, D. I., et al. Influence of oxidation states on plutonium mobility during long-term transport through an unsaturated subsurface environment. Environ. Sci. Technol. 38 (19), 5053-5058, (2004).

2. Taylor, D. M. Environmental plutonium - Creation of the universe to twenty-first century mankind in Plutonium in the Environment,., 1, 1-14 (2001).

3. Maher, K., Bargar, J. R., Brown, G. E. Environmental Speciation of Actinides. Inorganic Chemistry. 52 (7), 3510-3532, (2013). 
4. Kurosaki, H., Kaplan, D. I., Clark, S. B. Impact of environmental curium on plutonium migration and isotopic signatures. Environ. Sci. Technol. 48 (23), 13985-13991, (2014).

5. Orlandini, K. A., Penrose, W. R., Nelson, D. M., Pu(V) as the stable form of oxidized plutonium in natural-waters. Marine Chemistry. 18 (1), 49-57, (1986).

6. Kaplan, D. I., et al. Eleven-year field study of Pu migration from Pu III, IV, and VI sources. Environ. Sci. Technol. 40 (2), $443-448,(2006)$.

7. Morgenstern, A., Choppin, G. R., Kinetics of the oxidation of Pu(IV) by manganese dioxide. Radiochim. Acta. 90 (2), 69-74, (2002).

8. Davison, W., Zhang, H. In-situ speciation measurements of trace components in natural-waters using thin-film gels. Nature. 367 (6463), 546-548, (1994).

9. Zhang, H., Davison, W. Diffusional characteristics of hydrogels used in DGT and DET techniques. Anal. Chim. Acta. 398 (2-3), 329-340, (1999).

10. Cusnir, R., Steinmann, P., Bochud, F., Froidevaux, P. A DGT Technique for Plutonium Bioavailability Measurements. Environ. Sci. Technol. 48 (18), 10829-10834, (2014).

11. Froidevaux, P., Steinmann, P., Pourcelot, L. Long-Term and Long-Range Migration of Radioactive Fallout in a Karst System. Environ. Sci. Technol. 44 (22), 8479-8484, (2010).

12. Bajo, S., Eikenberg, J. Preparation of a stable tracer solution of plutonium (IV). Radiochim. Acta. 91 (9), 495-497, (2003).

13. Saito, A., Roberts, R. A., Choppin, G. R. Preparation of solutions of tracer level plutonium (V). Anal. Chem. 57 (1), 390-391, (1985).

14. Bajo, S., Eikenberg, J. Electrodeposition of actinides for alpha-spectrometry. Journal of Radioanalytical and Nuclear Chemistry. 242 (3), 745-751, (1999).

15. Dai, X. X., Christl, M., Kramer-Tremblay, S., Synal, H. A. Ultra-trace determination of plutonium in urine samples using a compact accelerator mass spectrometry system operating at 300 kV. Journal of Analytical Atomic Spectrometry. 27 (1), 126-130, (2012).

16. Christl, M., et al. The ETH Zurich AMS facilities: Performance parameters and reference materials. Nuclear Instruments and Methods in Physics Research B. 294, 29-38, (2013).

17. Blinova, O., et al. Redox interactions of $\mathrm{Pu}(\mathrm{V})$ in solutions containing different humic substances. Journal of Alloys and Compounds. 444, 486-490, (2007). 